3 Keisuke Kuroda, ${ }^{\dagger *}$ René Itten, ${ }^{\dagger}$ Lubomira Kovalova, ${ }^{\dagger}$ Christoph Ort, ${ }^{\dagger}$ David Weissbrodt ${ }^{\dagger}$ and

4 Christa S. McArdell ${ }^{\dagger}$

$5+$ Eawag, Swiss Federal Institute of Aquatic Science and Technology, Überlandstrasse 133,

6 Dübendorf 8600, Switzerland

$7 \ddagger$ Graduate School of Engineering, The University of Tokyo, 7-3-1 Hongo, Bunkyo, Tokyo

8 113-8656, Japan

$9{ }^{*}$ NIES, National Institute for Environmental Studies, 16-2 Onogawa, Tsukuba, Ibaraki 10 305-8506, Japan.

11 Corresponding author: keisukekr@gmail.com, Phone: +81 29850 2843, Fax: +81 29850 $12 \quad 2920$

13

\section{Hospital-use pharmaceuticals in Swiss waters modeled at high spatial resolution}


ABSTRACT

20 A model to predict the mass flows and concentrations of pharmaceuticals predominantly used

21 in hospitals across a large number of sewage treatment plant (STP) effluents and river waters

22 was developed at high spatial resolution. It comprised 427 geo-referenced hospitals and 742 STPs serving $98 \%$ of the general population in Switzerland. In the modeled base scenario, domestic, pharmaceutical use was geographically distributed according to the population size served by the respective STPs. Distinct hospital scenarios were set up to evaluate how the predicted results were modified when pharmaceutical use in hospitals was allocated differently; for example, in proportion to number of beds or number of treatments in hospitals. The hospital scenarios predicted the mass flows and concentrations up to 3.9 times greater than in the domestic scenario for iodinated X-ray contrast media (ICM) used in computed tomography (CT), and up to 6.7 times greater for gadolinium, a contrast medium used in magnetic resonance imaging (MRI). Field measurements showed that ICM and gadolinium were predicted best by the scenarios using number of beds or treatments in hospitals with the specific facilities (i.e., CT and/or MRI). Pharmaceuticals used both in hospitals and by the general population (e.g., cyclophosphamide, sulfamethoxazole, carbamazepine, diclofenac) were predicted best by the scenario using the number of beds in all hospitals, but the deviation from the domestic scenario values was only small. Our study demonstrated that the bed number-based hospital scenarios were effective in predicting the geographical distribution of a diverse range of pharmaceuticals in STP effluents and rivers, while the domestic scenario was similarly effective on the scale of large river-catchments.

KEYWORDS: benzotriazole; carbamazepine; catchment; cyclophosphamide; diatrizoate; diclofenac; fluconazole; furosemide; gabapentin; gadolinium; hospitals; iobitridol; iodinated X-ray contrast media (ICM); iohexol; iomeprol; iopamidol; iopromide; ioxitalamic acid; 
43

44

45

46

47

48

49

50

51

52

53

54

55

56

57

58

59

60

61

62

63

64

65

66 67 and powdered activated carbon. ${ }^{24-26}$ Several countries have already begun to consider the

modeling; oxazepam; ritonavir; river; sewage treatment plant (STP); sulfamethoxazole; verapamil

\section{INTRODUCTION}

Hospitals are often discussed as potential point sources for the discharge of numerous human-use pharmaceuticals into the environment, with major contributions to wastewater loads. ${ }^{1-4}$ Case studies have shown that the contribution of hospital wastewater to pharmaceutical loads in sewage treatment plants (STPs) varies considerably, from less than $5 \%$ to more than $50 \%$, depending on the specific hospital characteristics (location, type, size, and number relative to the catchment population) and the target substance. ${ }^{3,5-9}$ The number of hospital beds per 1000 population is a general measure of inpatient services availability, and varies among countries; for example, 0.3 (Bangladesh), 2.5 (China), 2.9 (world average), 3.2 (U.S.), 5.5 (Switzerland), 8.4 (Germany) and 14.1 (Japan), as of $2005 .^{10}$ The values found in specific catchment studies on hospital wastewater were 0.5-4.4 (Australia), ${ }^{5,7} 3.6-3.8$ (Switzerland), ${ }^{1,9} 4.4$ (Oslo), ${ }^{11} 6.5$ (Italy), ${ }^{12}$ and 12.1 (Berlin). ${ }^{13}$ The environmental impact of pharmaceutical residues in hospital wastewater has been studied. ${ }^{6,9,14,15}$ Pharmaceuticals of particular concern include iodinated X-ray contrast media (ICM), which are used for computed tomography (CT) in large quantities; ${ }^{16}$ cytostatics, which are often toxic; ${ }^{17}$ and antibiotics, which contribute to the spread of antibiotic resistance. ${ }^{4,18}$ In conventional sewage treatment processes, these pharmaceuticals are only partially eliminated, and their residues are found in surface and groundwater. ${ }^{19-21}$

Thus far, two options have been proposed for reducing environmental discharge of hospital-derived pharmaceuticals: (1) separate treatment of hospital wastewater at the source, ${ }^{22,23}$ and (2) upgrading municipal STPs to include post-treatments such as ozonation 
latter; in Switzerland, for example, a general $80 \%$ reduction in organic micropollutants from raw sewage, evaluated by selected compounds, is envisaged for roughly 100 STPs by a new water protection act. ${ }^{27,28}$

Both options above naturally involve massive costs. Therefore, in deciding whether a given STP and/or hospital should be modified for the elimination of pharmaceuticals, it is essential to identify which catchments have high loads or high concentrations of pharmaceuticals in the receiving waters. In large geographical areas with multiple substances, such assessments can be very laborious when based on field monitoring; and in such cases, modeling approaches are more useful. ${ }^{29,30}$ The discharge of domestically used compounds has been successfully modeled using catchment-scale water quality models, such as GREAT-ER, ${ }^{31}$ LF2000-WQX, ${ }^{32}$ or similar approaches. ${ }^{29,33}$ In these models, however, hospitals are not included as emission sources. Recently, Al Aukidy et al. ${ }^{8}$ proposed a framework for assessing the environmental risk posed by pharmaceuticals derived from hospital wastewater. They proposed to use pharmaceutical concentrations in hospital wastewater reported in various countries as reference concentrations, and use total hospital bed numbers in catchments to estimate the dilution of the hospital wastewater by domestic wastewater. In their study, the estimated risk quotient had an uncertainty of $2-3$ orders of magnitude, owing to the large variation in pharmaceutical concentrations in hospital wastewater in the literature. This uncertainty increases in the case of pharmaceuticals not used in every hospital but only in specific types of hospital; here, the spatial distribution of such pharmaceuticals would differ from that of hospital beds, a case not addressed by Al Aukidy et al. However, assessments based on actual consumption of pharmaceuticals in the target area, with consideration of hospital types, would greatly reduce such uncertainty. In Australia and Switzerland, audit data of pharmaceutical consumption obtained from hospitals was used to successfully estimate the hospital-based contribution to pharmaceutical loads in one or a few STPs. ${ }^{5,7}$ For assessment across a large 
93 number of catchments, however, a model using more easily-available data (e.g., number of 94 beds, hospital types) is more convenient in terms of data collection and modeling. In 95 Germany, the mass flow of ICM in the urban water cycle of Berlin was predicted by a model 96 comprising 12 STPs and hospitals, using estimated ICM consumption data. ${ }^{34}$ Thus far,

97 however, there has been no study on the modeling of different classes of hospital-use 98 pharmaceuticals across a large number of catchments, with consideration of hospital type.

99 Here, we proposed and validated a model-based method using national consumption data to 100 efficiently predict the geographical distribution of a diverse range of pharmaceuticals 101 (including some specifically used in hospitals) in STP effluents and rivers, at high spatial 102 resolution, incorporating multiple types of hospitals as geo-referenced point sources, across 103 all of Switzerland. The model is based on a previously developed national substance flow 104 model, which predicted the respective amounts of micropollutants discharged by the general 105 population. ${ }^{29}$ Our objectives were to (i) test and compare distinct scenarios with different 106 levels of model complexity (i.e., pharmaceuticals were geographically distributed according 107 to (a) population size served by respective STPs, (b) total number of hospital beds, (c) number 108 of beds at specific hospitals, or (d) number of medical treatments related to specific 109 pharmaceutical usage); (ii) test different cases for varying ratios of outpatients to total 110 patients; (iii) validate the model through field measurements; and (iv) evaluate the 111 applicability of the model in terms of spatial resolution, model complexity, data acquisition 112 demands, and predictive uncertainty.

\section{2. EXPERIMENTAL SECTION}

\section{$115 \quad 2.1$ Model setup}

116 As a basis, we used a substance flow model for Switzerland. ${ }^{29}$ The model incorporates a total 117 of 742 STPs, covering more than $98 \%$ of the general population ( 7.31 million). The input data 
118 are (i) national pharmaceutical consumption data, (ii) excretion rates of pharmaceuticals, (iii)

119 elimination rates in municipal STPs, (iv) location and population of the catchments, and (v)

120 dilution in the receiving waters. No elimination was assumed in the rivers, as the

121 environmental half-lives of many pharmaceuticals are on the same order of magnitude or

122 larger than the maximum residence time of Swiss rivers $(1 \mathrm{~d})$. The base flow conditions $\left(\mathrm{Q}_{347}\right)$

123 were used to account for minimum dilution in the rivers. Geographically, the total national

124 pharmaceutical loads were allocated proportionally to the population size of the respective

125 STP catchments, which ranged from 30-390,000 (average 9900, median 2700).

126 The national pharmaceutical consumption data for 2009 was purchased from IMS Health

127 (Danbury, CT, USA), which collects data in many countries, which is used for scholarly

128 research. ${ }^{35}$ In Switzerland, data are available on the overall national distribution of all

129 registered pharmaceuticals by manufacturers, importers, wholesalers and suppliers, divided

130 into four distribution channels: (i) pharmacies, (ii) drug stores, (iii) doctors' offices, and (iv)

131 hospitals. The sum of channels (i)-(iii), plus the amount dispensed through hospitals but

132 excreted outside by outpatients, is considered as the total consumption by the general

133 population (domestic consumption). Only the amount dispensed and excreted in hospitals

134 (e.g., by inpatients) is assumed to be discharged from hospitals. This amount, as a fraction of

135 total consumption, is thus referred to in this study as the effective hospital fraction (HF),

136 which describes the allocation of pharmaceuticals between hospitals and households. HF was

137 determined in the following manner. First, for each pharmaceutical, the ratio of the total

138 amount dispensed through hospitals (i.e., channel (iv) above) to total consumption was termed

139 the hospital-dispensed fraction $\left(\mathrm{HF}_{\mathrm{dis}}\right)$. Based on $\mathrm{HF}_{\mathrm{dis}}$, $\mathrm{HF}$ was estimated as the fraction of

140 the total amount of a given pharmaceutical dispensed through all hospitals, minus the portion

141 of this amount excreted by outpatients outside the hospitals. Hence, the consumed amount 
142 that was subsequently discharged from hospitals was expressed as (total consumption $\times$ HF),

143 and that discharged from the general population as (total consumption $\times(1-\mathrm{HF})$ ).

144 The hospital-allocated pharmaceutical consumption (i.g., total consumption $\times$ HF) was 145 distributed to the respective hospitals according to the scenarios described in Section 2.3. The 146 consumption by the general population (i.g. total consumption $\times(1-\mathrm{HF}))$ was distributed in 147 proportion to the respective catchment populations. The respective consumption by hospitals 148 and by the general population was assigned for each STP, and the resulting loads and 149 concentrations of pharmaceuticals in STP effluents and rivers were predicted, taking excretion

150 from the human body and elimination at STPs into account, as in the base model. ${ }^{29}$ This

151 allocation of pharmaceutical consumption to STP catchments is illustrated in Figure S1 of the 152 Supporting Information (hereafter, SI).

\subsection{Hospital data}

155 Information on the hospitals' location, type and number of inpatient beds was derived from 156 the official database of 2007 (Federal Office of Public Health), which included all the 157 hospitals in Switzerland (427 hospitals, with 44,892 beds in total). In addition, for hospitals 158 with radiology and/or oncology departments, information on the respective facilities, as well 159 as the actual numbers of treatments related to CT, MRI and inpatient chemotherapies, was 160 acquired. Further details of the data acquisition are described in S1 (SI). The number of in-use 161 beds was determined based on the occupancy rate for each hospital (median 90\%, Q1 84\%, 162 Q3 98\%), and used for subsequent modeling and analysis, including the characteristic hospital 163 bed density per 1000 population (hereafter, $\mathrm{B}_{1000}$ ).

164 In Switzerland, hospitals and hospital beds are concentrated in the large cities (Figures S2 and $165 \mathrm{~S} 3 \mathrm{a})$. In comparison, $\mathrm{B}_{1000}$ provides a different picture (Figure S3b): several suburban 166 catchments had higher $B_{1000}$ values of up to 118 , which is 21 times the national average $B_{1000}$ 
167 for Switzerland (5.5). More details on the geographical distribution of hospitals and hospital

168 beds, and the distribution of $\mathrm{B}_{1000}$ are described in $\mathrm{S} 2$.

169

170

\subsection{Scenarios}

171 Five distinct scenarios were developed for distributing pharmaceuticals (Table 1). Four of

172 these were the hospital scenarios, in which hospital-allocated pharmaceutical consumption

173 was distributed over the number of hospital beds or specific treatments. For contrast media

174 and cytostatics, hospitals equipped with CT or MRI facilities, and hospitals with oncology

175 departments, were distinguished in bed-specific and treatment-specific scenarios.

176 Furthermore, for each pharmaceutical, the effect of HF variation was evaluated for two cases;

177 in the average case $(\mathrm{AC}), \mathrm{HF}_{\mathrm{ac}}$ was set according to a realistic average proportion of expected

178 inpatients; in the high case $(\mathrm{HC}), \mathrm{HF}_{\mathrm{hc}}$ was set at the same value as $\mathrm{HF}_{\mathrm{dis}}$ or slightly lower,

179 conservatively assuming a higher proportion of inpatients than the average case. The domestic

180 scenario was evaluated in comparison with the hospital scenarios. In the domestic scenario,

181 all the pharmaceutical consumption was allocated to the general population (i.e., $\mathrm{HF}=0$ ), as

182 in the base model.

183

$184 \quad 2.4$ Input data uncertainty

185 For the base model, the maximum uncertainty in the predicted pharmaceutical load 186 discharged from each STP, through variation of the model parameters, was evaluated as

$18764 \%{ }^{29}$ In rivers, the uncertainty of $\mathrm{Q}_{347}$ added further uncertainty, ranging from $30-70 \%$, to

188 the predicted concentrations, depending on the river size. These uncertainties naturally

189 applied to the hospital scenarios as well. In addition, the uncertainty of the hospital data per

190 se must be accounted for. Briefly, the uncertainty was small $(<10 \%)$ for basic hospital data,

191 pharmaceutical consumption, and $\mathrm{HF}_{\mathrm{dis}}$. In comparison, large uncertainty was found for 
192 treatment numbers of MRI and chemotherapy. In 49\% of hospitals equipped with MRI

193 facilities, and $74 \%$ of hospitals with an oncology department, treatment numbers were not 194 available, and thus had to be estimated. The actual treatment numbers (where available) did 195 not show a good correlation with the bed numbers (Figures S4b and S4c). Therefore, for each

196 hospital type (e.g., supply hospitals, primary care hospitals), the median of the actual 197 treatment numbers (SI, Table S1) was used, in order to avoid extreme over- or 198 underestimation. In contrast, the actual CT treatment numbers highly correlated with the bed 199 numbers (Pearson, $r=0.92, P<0.001$; Figure S4a). Therefore, in 54\% of CT hospitals where 200 treatment numbers were not available, linear regression using the respective bed numbers was 201 employed, and thus the uncertainty was expected to be small. Further details on the 202 uncertainty regarding input data for the hospital scenarios are described in S3.

\section{$204 \quad 2.5$ Pharmaceuticals}

205 We modeled and measured 19 compounds, including 11 major pharmacological classes.

206 Escher et al. ${ }^{6}$ provide a list of the top 100 pharmaceuticals used and excreted in the largest 207 amounts in a typical and regionally important general hospital in Switzerland. Based on this 208 list, we selected pharmaceuticals which were representative and poorly eliminated during 209 sewage treatment. We studied seven ICM used for CT (Table 2), representing the 210 pharmacological class which showed the highest consumption and was mainly dispensed in 211 hospitals $\left(\mathrm{HF}_{\mathrm{dis}}=0.58\right)$. The seven $\mathrm{ICM}$ were modeled altogether as 'iodine', which was the 212 sum of the iodine content of all the ICM. This was because the occurrence of ICM measured 213 in the STP effluents varied significantly among catchments (Figure S5), seemingly owing to 214 varying hospital preferences. Gadolinium complexes are used for MRI as contrast media, and 215 are dispensed only in hospitals $\left(\mathrm{HF}_{\mathrm{dis}}=1\right)$. Therefore, gadolinium $(\mathrm{Gd})$ is most useful for 216 studying the discharge of hospital effluents to STPs. ${ }^{5,36}$ Gadolinium complexes are designed 
217 to be stable and non-reactive, and are quickly excreted from the human body, with a 1.3-2 $\mathrm{h}$

218 half-life. ${ }^{36,37}$ In addition, they are not removed during conventional sewage treatment. ${ }^{38}$

219 Cyclophosphamide was selected as a model cytostatic, because it is used only for 220 chemotherapy and has a large $\mathrm{HF}_{\text {dis }}(0.68)$. Sulfamethoxazole $\left(\mathrm{HF}_{\mathrm{dis}}=0.17\right)$ was selected 221 because of its broad use as an antibiotic in general hospitals. In addition, we selected eight 222 more pharmaceuticals with relatively small $\mathrm{HF}_{\text {dis }}(0.03-0.49)$. Benzotriazole, which is closely 223 related to domestic wastewater (i.e., $\mathrm{HF}_{\mathrm{dis}}=0$ ), was selected as a reference compound. ${ }^{39}$ The 224 modeled compounds included four of the five originally proposed indicator compounds used 225 to evaluate the removal of micropollutants in advanced wastewater treatment as envisaged in 226 the new Swiss water protection act. ${ }^{27,28}$ Excretion rates and elimination in STP were based on 227 averages from literature data. The parameters and scenarios for the ICM, gadolinium, 228 cyclophosphamide and sulfamethoxazole are shown in Table 2; and those for the remaining 229 compounds, in Table S2.

\section{$231 \quad 2.6$ Field sampling and laboratory analyses}

232 Samples of 14 STP effluents and 7 river waters in Switzerland (Table S3; locations are 233 indicated in Figures 1 and S3b) were collected during June and October, 2010. The sampling 234 sites were selected based on meeting at least one of the following criteria: catchments with 235 large variation in predictions between the hospital scenarios and the domestic scenario; 236 catchments with hospitals equipped with CT or MRI facilities, or an oncology department; 237 locations with high predicted mass flows or concentrations. The STP catchments contained 238 varying combinations of general, psychiatric, and rehabilitation hospitals, with varying 239 proportions of hospital beds by hospital type (Table S4).

240 Details on the sampling methods, analytical procedures and quality control are described in 241 S4. Briefly, 24-h composite samples were taken over one week (STPs), and 1-, 2- or 4-week 
242 composite samples over 1-8 weeks (rivers). The compounds, excluding gadolinium, were 243 analyzed by online SPE-HPLC-MS/MS ${ }^{40}$ Gadolinium was analyzed using ICP/HRMS.

\subsection{Methods for scenario evaluation and model validation by measurement}

Throughout this study, we evaluated the pharmaceutical discharge based on mass flow (load).

247 For rivers, pharmaceutical mass flow was evaluated at each STP discharge point by 248 aggregating the loads from the upstream STPs. To compare the model predictions among the 249 different hospital scenarios, with respect to the domestic scenario, the modeled 250 pharmaceutical mass flow was evaluated as the change relative to the domestic scenario (i.e.,

251 mass flow predicted by a hospital scenario/mass flow predicted by the domestic scenario).

252 This relative change remained the same for all pharmaceutical concentrations, as the assumed

253 flows are the same in all the scenarios.

254 The measured pharmaceutical mass flows were determined by multiplying the measured 255 concentrations by the actual discharge over the sampling period, for each STP and river

256 (Table S5). The agreement between the respective calculated and modeled average daily mass

257 flows was evaluated, following Ort et al., ${ }^{29}$ using the predictive accuracy factor 258 (prediction/observation; hereafter, PAF), its median value (MPAF), its relative standard 259 deviation (RSD), and the $R^{2}$ from the linear regression forced through 0.

260 The benzotriazole mass flow predicted by the domestic scenario agreed well with the 261 measured mass flow, both in the STP effluents and the rivers (Figure S6); and this showed 262 that the domestic scenario was valid for predicting compounds used domestically.

263 Throughout the paper, evaluations are mainly based on the results for ICM, gadolinium, 264 cyclophosphamide and sulfamethoxazole. The predicted mass flow and concentrations of 265 those four compounds in all the STP effluents and river waters, along with their relative 266 change, are shown in Table S6. 
3. RESULTS

2693.1 Modeled pharmaceutical discharge

$270 \quad 3.1 .1$ STP effluents

271 Overall. Our results showed that the hospital scenarios predicted higher mass flows than the

272 domestic scenario only in a small number of catchments (Figures 1a, 2, S7-S9). In 76\% of all

273 catchments with $30-100,000$ population and no hospital beds, the change relative to the

274 domestic scenario was simply (1-HF) for all the hospital scenarios, because the catchments

275 had no hospital-allocated pharmaceutical consumption (see Figure S1 for the expected

276 relative change depending on catchment characteristics). Among all the scenarios, the relative

277 change exceeded 1 in $8-15 \%$ of catchments (Tables S7 and S8), where the number of hospital

278 beds or treatments per population were above the respective national average values (Table

279 S9). Large relative changes were found in a few percent of catchments, which were mostly

280 suburban or relatively remote, with $1000-10,000$ population. These catchments differed

281 among scenarios and compounds, depending on the services provided by the hospitals. In

282 contrast, in catchments with more than 100,000 population, the predicted mass flows varied

283 less among scenarios and compounds, and the relative change mostly ranged from $1-3$. This

284 indicated an abundance of hospitals of all types in these heavily populated catchments.

285 The all beds scenario had more catchments with large relative changes than the other 286 scenarios. This is because, in all beds, catchments containing any type of hospital are 287 assigned hospital-allocated pharmaceutical consumption. Therefore, a very large relative 288 change was found in catchments where the existence of hospitals of special types caused large 289 B $_{1000}$ (e.g., suburban catchments). In such catchments, the all beds scenario can overestimate 290 the mass flow of specific pharmaceuticals. For example, the relative change for ICM and 291 gadolinium in all beds was the largest (e.g., around 7 for ICM, AC) in the two small 
292 catchments of Rheinau and Schinznach-Bad (Figure 2), both of which have a population of 2931300 and the highest $B_{1000}$ values (118 and 108, respectively). However, this result is 294 unrealistic, because the catchments only contain a psychiatric hospital (Rheinau), and a 295 rehabilitation hospital (Schinznach-Bad), neither of which has a radiology department; and 296 the field measurements confirmed the overestimation of contrast media in these catchments 297 (Section 3.2.1).

298 Contrast media. The contrast media included $\mathrm{ICM}\left(\mathrm{HF}_{\mathrm{ac}}=0.3, \mathrm{HF}_{\mathrm{hc}}=0.5\right)$ and gadolinium $299\left(\mathrm{HF}_{\mathrm{ac}}=0.5, \mathrm{HF}_{\mathrm{hc}}=0.8\right)$. In the $C T$ beds scenario, the largest relative changes, of $3.9(\mathrm{AC})$ and $3005.8(\mathrm{HC})$, were found in STP Saignelegier (2100 population) and STP Zurzach (7500). 301 Gadolinium showed the largest relative change because it has the largest HF value. In the MRI 302 beds scenario, the largest relative changes (3.7-6.7 in AC, 5.3-10.1 in HC) were found in six 303 catchments, with varying population ranging from 2100-52,000. In the MRI treatments 304 scenario, the maximum relative change was even larger, at 22.4 (STP Saignelegier, HC); note, 305 however, that the treatment number in this catchment was estimated.

306 Other pharmaceuticals. Various HF values $\left(\mathrm{HF}_{\mathrm{ac}}=0.01-0.1, \mathrm{HF}_{\mathrm{hc}}=0.03-0.49\right)$ were applied 307 to the remaining ten pharmaceuticals. Among the latter, ritonavir had the largest relative 308 change (e.g., 3.1 in all beds, AC, STP Rheinau). In the case of cyclophosphamide $\left(\mathrm{HF}_{\mathrm{ac}}=\right.$ $\left.3090.05, \mathrm{HF}_{\mathrm{hc}}=0.34\right)$, the relative change reached 1.5 in the oncology beds and chemotherapy 310 scenarios for $\mathrm{AC}$, and 3.8 in oncology beds for $\mathrm{HC}$. Regarding sulfamethoxazole $\left(\mathrm{HF}_{\mathrm{ac}}=0.03\right.$, $\left.311 \mathrm{HF}_{\mathrm{hc}}=0.17\right)$, the relative change reached $1.7(\mathrm{AC})$ and $4.5(\mathrm{HC})$ in all beds, and $1.4(\mathrm{AC})$ and $3123.2(\mathrm{HC})$ in general beds.

313 Comparison between bed-specific scenarios and treatment-specific scenarios. The 314 respective predictions by the bed-specific and treatment-specific scenarios did not differ much 315 for ICM (Figure S10). In comparison, the difference was large for gadolinium (up to a factor 316 of 2) and cyclophosphamide (up to 4). This reflects the fact that bed and treatment numbers 
317 did not correlate well in the case of MRI and chemotherapy (Figures S4b and S4c). However,

318 missing treatment numbers produced large uncertainties (Section 2.4); therefore, great care

319 should be taken in the case of treatment-specific scenarios in such catchments.

320

321

\subsubsection{Rivers}

322 Similarly to STP effluents, the relative changes were largest in catchments with $1000-10,000$

323 upstream population (Figures 1b, S11-S13). The largest relative changes in rivers (e.g., 3.9

324 for ICM in CT beds, AC) were similar to those in STP effluents. However, large relative

325 changes were found in fewer river waters than STP effluents (Tables S10 and S11); for

326 example, relative changes of greater than 3 for gadolinium in MRI beds (AC) were noted in

327 effluents of six STPs but in only three river waters. All the scenarios predicted very similarly

328 in rivers where the upstream population exceeded 10,000. As the loads of all the upstream

329 STPs were aggregated, the respective differences from the domestic scenario were averaged

330 out.

331

332 3.2 Model validation by measurement

$333 \quad 3.2 .1$ Contrast media

334 As explained above, the all beds scenario was inappropriate for modeling ICM and 335 gadolinium (e.g., MPAF 3.0, RSD 469\% for ICM, AC; Figure 3, and Tables S12 and S13).

336 Especially in the STP catchments of Rheinau and Schinznach-Bad, the all beds scenario

337 considerably overestimated the contrast media (PAF 11-55), because the catchments did not

338 have CT or MRI facilities. In contrast, the facility-specific scenarios showed better agreement

339 with the measured values (e.g., PAF 1.2-3.6 in MRI beds, AC) in those catchments.

340 The domestic, CT beds and CT treatments scenarios somewhat overestimated ICM in the STP

341 effluents (MPAF 1.5-2.5, AC; Figure 3a), although the magnitude of overestimation was not 
342 markedly higher than the base model uncertainty. The observed overestimation may have 343 partly derived from the uncertainties of consumption numbers and/or the varying elimination 344 rates of ICM in the STPs. The reported elimination of ICM varied largely (e.g., 0-90\% for 345 iopromide), possibly due to varying sludge age and/or degree of nitrification. ${ }^{20,41-43}$ In our 346 model, an average elimination rate of $40 \%$ was assumed (Table 2). Among the scenarios, 347 domestic had an MPAF closest to 1, with the largest $R^{2}$ value (Figure 3a), but the deviation 348 from the measured values was found to be large (PAF 0.27-7.7). In contrast, the $C T$ beds and 349 CT treatments scenarios in AC showed smaller RSD values, and deviated less from the 350 measured values (PAF 0.48-5.8). Among the sampled STPs, four catchments showed relative 351 changes of greater than 2 in $C T$ beds, AC. The domestic scenario underestimated the 352 measured values in two of these catchments (PAF 0.27 and 0.48 in domestic, against 0.82 and 3531.1 in $C T$ beds), and $C T$ beds overestimated them in the other two (PAF 2.5 and 4.6, 354 respectively, against 1.2 in domestic).

355 In the case of gadolinium, the mass flows predicted by the MRI beds and MRI treatments 356 scenarios, AC, agreed better with the measured STP effluent mass flows (MPAF 0.79, RSD $357152 \%, R^{2} 0.93$ in MRI beds and 1.0, 99\%, 0.96 in MRI treatments; Figure 3b) than those of 358 the domestic scenario $(0.56,323 \%, 0.71)$. The advantage of the hospital scenarios was clearly 359 demonstrated in the case of gadolinium, probably because predictions of gadolinium showed 360 the largest difference among scenarios (due to the large HF), and because uncertainty in the 361 elimination rate was very small owing to gadolinium's high persistence during conventional

362 sewage treatment processes. ${ }^{38}$ Five measured STP catchments exhibited relative changes of 363 greater than 2 in MRI beds (AC). The domestic scenario underestimated the measured values 364 in four of these catchments (PAF 0.13-0.37 in domestic against $0.55-2.4$ in MRI beds). In the 365 remaining STP, Langnau (indicated in Figures 3, S14 and S15), the catchment's PAF was 366 better in domestic (0.88) than in MRI beds (4.0), and the ICM values were also predicted 
367 better by the domestic scenario. In this catchment, CT and MRI facilities were only installed

368 two months before the sampling campaign, and therefore usage of contrast media was

369 probably still low, which may explain the overestimation by the hospital scenarios.

370 In three catchments where the treatment numbers were all actual numbers, the respective PAF

371 values for MRI treatments, AC $(0.59,0.75$ and 0.81$)$, were similar to those for MRI beds, AC

$372(0.79,0.55$ and 0.61$)$. In five catchments where all the treatment numbers were estimated,

373 MRI treatments (AC) predicted well compared to the catchments with actual treatment

374 numbers, but showed greater variation (PAF 0.99-2.8, median 1.6).

375 More catchments exhibited over- or underestimation in $\mathrm{HC}$ than in AC, for both ICM and

376 gadolinium (Figures S14 and S15), which shows that the assumed $\mathrm{HF}_{\mathrm{hc}}$ was too large.

377 In rivers, the contrast media were predicted well by both bed-specific scenarios and

378 treatment-specific scenarios in AC (e.g., MPAF 1.8, RSD 32\%, $R^{2} 1.00$ in CT beds; and 0.67, $37938 \%, 1.00$ in MRI beds; Figures S14 and S15).

380

$381 \quad 3.2 .2$ Other pharmaceuticals

382 The predictions for the other pharmaceuticals in AC did not differ much among scenarios, and 383 mostly agreed with measured loads (within a factor of 2), both in the STPs and rivers (Figures

384 S16-S19, Tables S12-S15). Interestingly, however, for cyclophosphamide, sulfamethoxazole,

385 carbamazepine and diclofenac, the all beds scenario generally predicted better than domestic

386 and general beds in the STP catchments where psychiatric and/or rehabilitation hospitals

387 accounted for more than half of the total hospital beds (e.g., in STP Rheinau, for

388 cyclophosphamide, PAF 0.93 in all beds, compared with $<0.46$ in the other scenarios). This

389 suggests that the special types of hospital discharged these pharmaceuticals, unlike the

390 contrast media, at rates similar to general hospitals. Overall, these results suggest that

391 incorporating hospitals as point sources is important in catchments with high $\mathrm{B}_{1000}$, even for 
392 compounds with small HF; and that great care should be taken when estimating

393 pharmaceutical discharges from small catchments with high $\mathrm{B}_{1000}$.

394

395

\section{DISCUSSION}

\subsection{Parameters and scenarios}

397 Our results showed that, in a large proportion $(>95 \%)$ of both STP effluents and rivers in

398 Switzerland, the predictions of the hospital scenarios did not differ much from those of the

399 domestic scenario (e.g., relative change $<1.5$ ). In a few percent of catchments and rivers,

400 however, the difference from the domestic became larger, and the hospital scenarios showed

401 greater predictive accuracy. For example, in the all beds scenario, with $\mathrm{HF}=0.3$, the largest

402 relative change was 7.2, and the relative change exceeded 2 in 24 of the STP catchments,

403 serving $2.1 \%$ of the national population $(158,000)$. The magnitude of the difference from

404 domestic values depended on $\mathrm{B}_{1000}$ and HF (see also S5 and Figure S20 for theoretical

405 explanation). HF is the most critical model parameter in determining the allocation of

406 pharmaceuticals between hospitals and households; the other parameters, such as excretion

407 and elimination, have no effect on this allocation. The large impact of HF variation on the

408 model predictions was demonstrated by the two cases, AC and HC. With a large HF of 0.8,

409 the change relative to the domestic scenario could reach 22. Nevertheless, the agreement

410 between the modeled and measured loads was generally better when HF was set at half of

$411 \mathrm{HF}_{\mathrm{dis}}$ or less. This shows that a significant fraction of pharmaceuticals dispensed within

412 hospitals were discharged outside the hospitals, and that HF is therefore meaningful only if it

413 is reduced from $\mathrm{HF}_{\text {dis }}$ by the appropriate portion of outpatients (see Section 2.1). It should

414 also be noted that, even for general pharmaceuticals with small HF, the relative change can be

415 large in catchments with high hospital bed density, where the hospital scenarios predict better

416 than the domestic scenario (see 3.2.2). The hospital bed density can vary widely (e.g., up to 21 
417 times the national average in Switzerland; see S2), often owing to the presence of special

418 hospital types (e.g., psychiatric or rehabilitation hospitals). In this study, these special types of

419 hospital were, like general hospitals, found to be the sources of many general 420 pharmaceuticals, favoring the all beds scenario. On the other hand, in the case of 421 pharmaceuticals used for specific treatments (i.e., in this study, ICM and gadolinium), the all

422 beds scenario should not be applicable, and the relevant hospitals must be distinguished in 423 bed-specific or treatment-specific scenarios. For such pharmaceuticals, bed-specific scenarios 424 are typically more reliable than treatment-specific scenarios, because (as in the present study) 425 bed numbers and occupancy are far more easily accessed and have smaller uncertainties in 426 estimation than treatment numbers. In the cases where treatment numbers were available in 427 this study, however, the measured values agreed as well with the predictions of the 428 treatment-specific scenarios as they did with those of the bed-specific scenarios.

429 The data used for the hospital scenarios can change over time, although typically not rapidly 430 (e.g., 2\% annual change in Switzerland; see S3). Thus, these data would need to be updated 431 regularly (e.g., every few years). In the case of pharmaceuticals used for specific treatments 432 (e.g., ICM, gadolinium), information such as the establishment or abolishment of 433 corresponding facilities must be updated; otherwise, the discharge from hospitals may be 434 significantly over- or underestimated.

\section{$436 \quad 4.2$ Applicability}

437 Through the comparison of different scenarios, our study revealed the relationship between 438 spatial resolution, model complexity and predictive accuracy. At low spatial resolution (e.g., 439 large river-catchments), the difference between scenarios was very small for all the 440 pharmaceuticals tested, as shown in the results of rivers with large upstream population. In 441 contrast, at high spatial resolution (e.g., STP catchment or small river-catchments), the 
442 difference was larger, and the hospital scenarios showed good predictive accuracy (e.g.,

443 within a factor of 2). In this case, the domestic scenario could produce discrepancies of up to

4441 order of magnitude.

445 Therefore, at low spatial resolution, the domestic scenario is a simple and efficient model for 446 predicting the distribution of a diverse range of pharmaceuticals. Incorporating geo-referenced 447 STP and pharmaceutical consumption data, the domestic scenario is suitable for identifying 448 potential river catchments of concern in a large geographical area (e.g., at the national or 449 regional level). Our results suggest that other, population-based models for predicting the 450 discharge of domestic-use compounds (e.g., carbamazepine and diclofenac) ${ }^{31-33}$ can also 451 accurately predict hospital-use pharmaceuticals on the scale of large catchments of rivers.

452 In contrast, the hospital scenarios can be used most effectively at high spatial resolution.

453 These scenarios additionally incorporate geo-referenced hospital data; information on hospital 454 type, bed number and bed occupancy; and HF. Therefore, the hospital scenarios are most 455 suitable for the detailed evaluation of smaller regions of interest (e.g., at the county or 456 prefectural level), or catchments of particular rivers, where the related data-collection efforts 457 are justified. Large relative changes (vs. the domestic scenario) were found mostly in 458 suburban STPs and small rivers with high catchment $\mathrm{B}_{1000}$. Nevertheless, large cities also 459 tended to have a relatively high $\mathrm{B}_{1000}$, and thus significant relative change (up to 3). Therefore, 460 the hospital scenarios are also useful for urban STPs and their adjacent receiving waters.

461 Through field measurement, we validated our scenarios in STP catchments of various sizes 462 (1300-52,000 population). In both the hospital scenarios and domestic scenario, the predictive 463 uncertainty was less than the uncertainty in the approach of Al Aukidy et al. ${ }^{8}$ (e.g., 2-3 orders 464 of magnitude), who used measurement-derived concentrations from the literature instead of 465 hospital consumption data. This demonstrates a significant advantage of our 466 consumption-based approach. To further improve the model's predictive accuracy, the input 
467 data that were here assumed to be geographically and temporally constant (for model 468 simplicity and wide applicability) may be refined; for example, as suggested in Coppens et 469 al., ${ }^{33}$ by incorporating variability in consumption depending on geographic, climatic, seasonal 470 and/or socio-cultural conditions; varying the elimination of pharmaceuticals according to 471 varying sewage treatment methods; and incorporating environmental attenuation in rivers.

472 Interestingly, a similar approach, in this case using pharmaceutical consumption and animal 473 production, was proposed for predicting the discharge of veterinary antibiotics. ${ }^{44}$

\subsection{Implications for pharmaceutical discharge reduction and risk assessment}

476 In this study, the predicted contribution of hospitals to the total discharge at a single STP was 477 up to $92 \%$ for gadolinium (MRI beds scenario, AC), $82 \%$ for ICM (CT beds, AC), and 55\% 478 for cyclophosphamide (all beds, AC). For catchments with such a large hospital contribution, 479 on-site treatment of hospital effluents ${ }^{40,45}$ would be efficient in reducing pharmaceutical 480 discharge from STPs, reducing losses into the environment through sewer leakage ${ }^{46}$ and

481 combined sewer overflows, ${ }^{47}$ and preventing hospital wastewater-derived pathogens and 482 antibiotic multiresistant bacteria ${ }^{4}$ from entering the environment.

483 Pharmaceutical concentrations in rivers can vary a great deal, as the predictions here reveal; 484 and in some rivers may be higher than has previously been determined. For example, in the 485 CT beds scenario here, a range of $0.2 \mathrm{ng} / \mathrm{L}$ to $40 \mu \mathrm{g} / \mathrm{L}$ (AC) and $58 \mu \mathrm{g} / \mathrm{L}$ (HC) was predicted 486 as the sum of the seven modeled ICM concentrations; whereas in German rivers, the 487 measured sum of several ICM was only a few $\mu \mathrm{g} / \mathrm{L} .{ }^{16,43}$ Therefore, the hospital scenarios may 488 be useful for revealing such hotspots, as well as for evaluating real and potential 489 environmental impacts, and for devising countermeasures. 
492 We thank A. Doberer (Labor Veritas); M. Lanfranchi and A. Koch (Amt für Natur und

493 Umwelt Graubünden); M. Langmeier (Eawag); J. Schenzel (Research Station Agroscope); C.

494 Stamm (Eawag); A. Strawczynski (Service des eaux, sols et assainissement Laboratoire 495 SESA); staff from STPs Bioggio, Davos, Füllinsdorf, Herisau, Langnau I.E., Leuggern, Muri, 496 Münsterlingen, Rancate/Mendrisio, Rheinau, Schinznach-Bad, St.Gallen-Hofen, Wil and 497 Zurzach for their help in sample collection for measurement. We thank A. Ammann, F. 498 Dorusch, A. Lück and the members of Department of Environmental Chemistry (Uchem), all 499 from Eawag, for their help in sample collection and analyses. IMS Health (Danbury, CT, 500 USA) provided Swiss pharmaceutical consumption numbers, and Bayer HealthCare 501 Pharmaceuticals (Berlin, Germany), Bracco (Milano, Italy) and Guerbet (Villepinte, France) 502 ICM consumption numbers, the Federal Office of Public Health (FOPH) information on 503 Swiss hospitals, the Federal Statistical Office of Switzerland (FSO) information on the 504 hospital types and facilities as well as the geocoordinates of all Swiss buildings (registered 505 constructions and lodgments), the Swiss Armed Forces (Logistikbasis der Armee, 506 Sanitärdienstes) the coordinates of the hospitals. This study was supported by the Swiss 507 Federal Office for the Environment (FOEN; contract no. 07.0142.PJ/H163-1663), the Swiss 508 cantons AG, BE, BL, GE, SG, SH, SO, SZ, TG, VD and ZH, the Swiss State Secretariat for 509 Education and Research (SER)/COST within COST Action 636 (Project C05.0135), the EU 510 project NEPTUNE (contract no. 036845, SUSTDEV-2005-3.II.3.2) within the Energy, Global 511 Change and Ecosystems Programme of the Sixth Framework (FP6-2005-Global-4), the 512 CREST project grant for 'Development of Well-balanced Urban Water Use System Adapted 513 for Climate Change' from the Japan Science and Technology Agency (JST), and Research 514 Fellowships for Young Scientists (\#21-04295) from Japan Society for the Promotion of 515 Science (JSPS). 


\section{SUPPORTING INFORMATION AVAILABLE}

518 Details of hospital data acquisition and uncertainty, information on the STPs and rivers for

519 field measurements, methods of sampling and analysis, QA/QC, and all results of predictions,

520 measurements and model validation. This information is available free of charge via the

521 Internet at http://pubs.acs.org.

522 


\section{FIGURES AND TABLES}

524

525

526

527

528

529

530

531

532

533

534

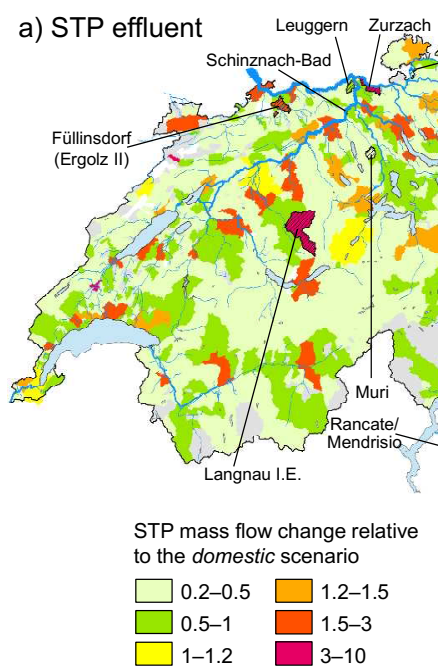

Rheinau Münsterlingen

Münsterl

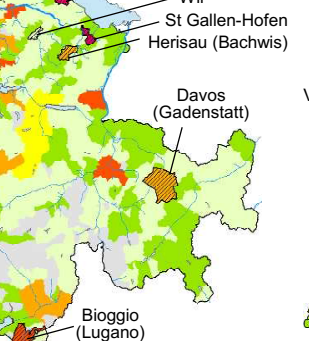

b) River

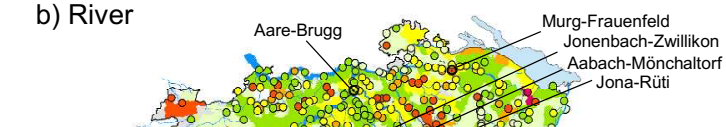

Venoge-Ecublens,

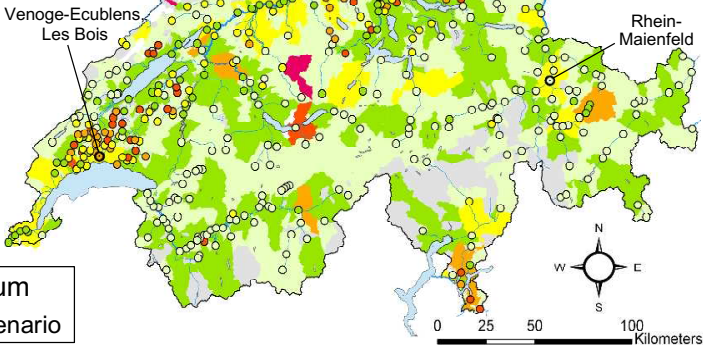
Gadolinium
$M R I$ beds scenario

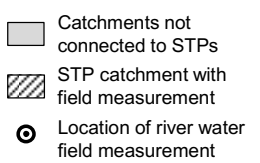

Concentration in rivers at STP discharge points

Change in river concentration relative to the domestic scenario $\mathrm{O} \leq 0.005 \mu \mathrm{g} / \mathrm{L} \quad \mathrm{O} 0.025-0.05 \mu \mathrm{g} / \mathrm{L} \square 0.2-0.5 \square 1.2-1.5$ $00.005-0.01 \mu \mathrm{g} / \mathrm{L} \quad 00.05-0.2 \mu \mathrm{g} / \mathrm{L} \quad \square \quad \square .5-1 \quad \square \quad \square=0.5$ $00.01-0.025 \mu \mathrm{g} / \mathrm{L} \quad 0.2-0.8 \mu \mathrm{g} / \mathrm{L} \quad \square 1-1.2 \square 3-10$

Figure 1. Predicted geographical distribution of gadolinium for (a) mass flow in STP effluents and (b) concentration in rivers. Gadolinium mass flow and concentrations are predicted by the MRI beds scenario (AC). The mass flow in STP effluents is shown as the change relative to the domestic scenario, using different colors for designated STP-catchment areas. For the rivers, the concentration change relative to the domestic scenario is shown using different colors for designated STP-catchment areas, and the predicted concentrations at the STP discharge points are indicated by different colored dots. The field measurement locations are also indicated, for both STP catchments and river waters. 

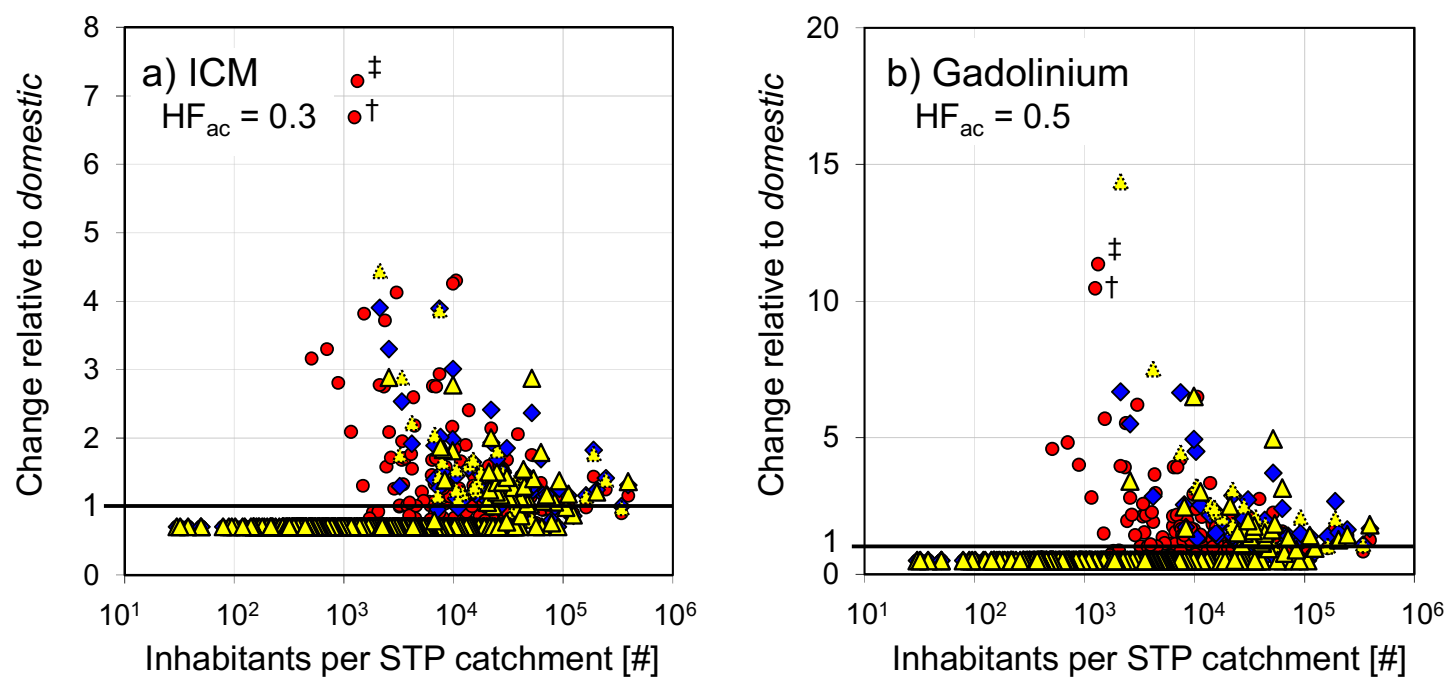

O All beds $\triangle \mathrm{CT} / \mathrm{MRI}$ beds $\triangle \mathrm{CT} / \mathrm{MRI}$ treatments $(<50 \%$ estimated) $\mathrm{ACT} / \mathrm{MRI}$ treatments $(\geq 50 \%$ estimated $)$ † STP Rheinau (with a psychiatric hospital) ‡ STP Schinznach-Bad (with a rehabilitation hospital)

536 Figure 2. The mass flow of (a) ICM and (b) gadolinium in STP effluents, relative to 537 catchment size, as predicted by the different hospital scenarios (average case). The mass flow 538 is shown as the change relative to the domestic scenario. Data of CT treatments and MRI 539 treatments are shown separately according to the ratio of the estimated treatment number $(<$ $54050 \%$ and $\geq 50 \%$ ) to the total treatment number in each catchment (see Table S6 for the data). 

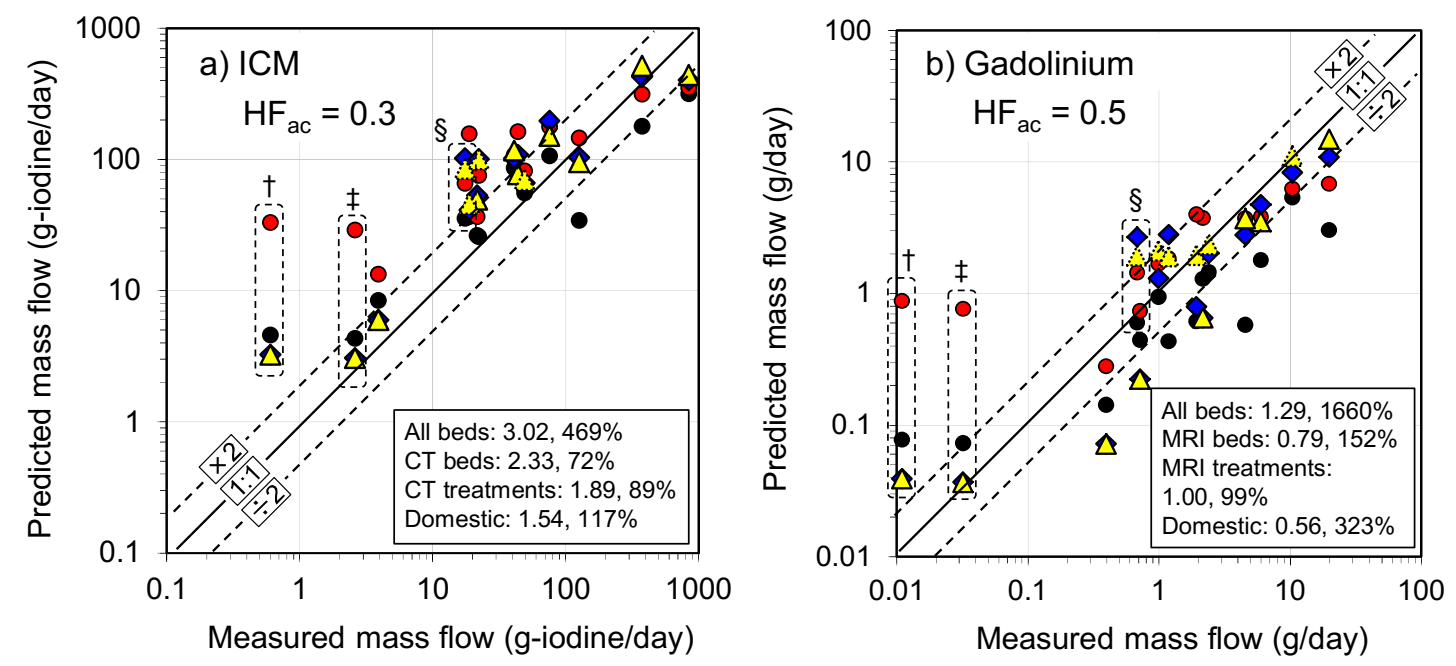

OAll beds $\triangle \mathrm{CT} / \mathrm{MRI}$ beds $\triangle \mathrm{CT} / \mathrm{MRI}$ treatments $(<50 \%$ estimated) $\mathrm{A} \mathrm{CT} / \mathrm{MRI}$ treatments $(\geq 50 \%$ estimated $)$ - Domestic

$$
\begin{aligned}
& \text { † STP Rheinau (with a psychiatric hospital) } \\
& \text { † STP Schinznach-Bad (with a rehabilitation hospital) } \\
& \text { § STP Langnau (CT and MRI were installed recently) }
\end{aligned}
$$

542

543 Figure 3. Comparison between the measured mass flow and the modeled flow of (a) ICM and

544 (b) gadolinium in STP effluents in different scenarios (average case). Data of CT treatments

545 and MRI treatments are shown separately according to the ratio of the estimated treatment

546 number $(<50 \%$ and $\geq 50 \%)$ to the total treatment number in each catchment (Table S4). The

547 MPAF and its RSD in each scenario are also shown in the figures. 
Table 1. Scenarios.

\begin{tabular}{|c|c|c|}
\hline scenarios & $\mathrm{HF}$ & distribution of pharmaceuticals \\
\hline \multicolumn{3}{|l|}{ hospital scenarios } \\
\hline all beds & $\begin{array}{l}\mathrm{HF}_{\mathrm{ac}} / \\
\mathrm{HF}_{\mathrm{hc}}\end{array}$ & $\begin{array}{l}\text { the consumption allocated to hospitals is distributed } \\
\text { over all hospital beds } \\
\text { the consumption allocated to hosnitals is distributed }\end{array}$ \\
\hline general beds & $\begin{array}{l}\mathrm{HF}_{\mathrm{ac}} / \\
\mathrm{HF}_{\mathrm{hc}}\end{array}$ & $\begin{array}{l}\text { over the beds in the general hospitals (hospitals } \\
\text { excluding psychiatric hospitals and rehabilitation } \\
\text { hospitals) }\end{array}$ \\
\hline $\begin{array}{l}\text { bed-specific scenarios: } \\
\text { CT beds } \\
\text { MRI beds } \\
\text { oncology beds }\end{array}$ & $\begin{array}{l}\mathrm{HF}_{\mathrm{ac}} / \\
\mathrm{HF}_{\mathrm{hc}}\end{array}$ & $\begin{array}{l}\text { the consumption of contrast media/cytostatics } \\
\text { allocated to hospitals is only distributed over the } \\
\text { beds of hospitals with their relevant departments, } \\
\text { respectively (CT, MRI and oncology department) }\end{array}$ \\
\hline $\begin{array}{l}\text { treatment-specific scenarios: } \\
\text { CT treatments } \\
\text { MRI treatments } \\
\text { chemotherapy }\end{array}$ & $\begin{array}{l}\mathrm{HF}_{\mathrm{ac}} / \\
\mathrm{HF}_{\mathrm{hc}}\end{array}$ & $\begin{array}{l}\text { the consumption of contrast media/cytostatics } \\
\text { allocated to hospitals is distributed over the number } \\
\text { of respective treatments (CT, MRI and } \\
\text { chemotherapy) }\end{array}$ \\
\hline \multicolumn{3}{|l|}{ domestic scenario } \\
\hline domestic & 0 & all the consumption is distributed over the population \\
\hline
\end{tabular}

550

551

552

553 
554 Table 2. Parameters used for modeling ICM, gadolinium, cyclophosphamide and 555 sulfamethoxazole.

\begin{tabular}{|c|c|c|c|c|}
\hline compound & ICM (as iodine)a & gadolinium & cyclophosphamide & sulfamethoxazole \\
\hline pharmaceutical group & contrast media & $\begin{array}{l}\text { contrast } \\
\text { media }\end{array}$ & cytostatic & antibiotic \\
\hline total consumption in Switzerland ( $\mathrm{kg} / \mathrm{year})^{b}$ & $16,064 c$ & $157^{d}$ & 28 & 2427 \\
\hline hospital-dispensed fraction $\left(\mathrm{HF}_{\text {dis }}\right)^{e}$ & 0.58 & 1 & 0.68 & 0.17 \\
\hline effective hospital fraction, average case $\left(\mathrm{HF}_{\mathrm{ac}}\right)^{f}$ & 0.3 & 0.5 & 0.05 & 0.03 \\
\hline effective hospital fraction, high case $\left(\mathrm{HF}_{\mathrm{hc}}\right)^{g}$ & 0.5 & 0.8 & 0.34 & 0.17 \\
\hline excretion rate (combined for urine and feces) & 0.97 & 1 & 0.2 & 0.45 \\
\hline elimination in STP & 0.40 & 0 & 0 & 0.65 \\
\hline \multicolumn{5}{|l|}{ Scenarios } \\
\hline all beds & $x$ & $x$ & $x$ & $x$ \\
\hline general beds & & & & $x$ \\
\hline CT beds & $x$ & & & \\
\hline CT treatments & $x$ & & & \\
\hline MRI beds & & $x$ & & \\
\hline MRI treatments & & $x$ & & \\
\hline oncology beds & & & $x$ & \\
\hline chemotherapy & & & $x$ & \\
\hline domestic & $x$ & $x$ & $x$ & $x$ \\
\hline literature for excretion/elimination & $1 / h$ & $38 /{ }^{38}$ & $48 / 48$ & $29 / 29,49$ \\
\hline
\end{tabular}

$556{ }^{a}$ Total iodine content of 7 ICM (diatrizoate, iobitridol, iohexol, iomeprol, iopamidol, 557 iopromide and ioxitalamic acid).

$558{ }^{b}$ According to 2009 consumption data from IMS Health (Danbury, CT, USA).

$559{ }^{c}$ Iodine content of 7 ICM was calculated using confidential 2009 consumption data 560 (information courtesy of Bayer HealthCare Pharmaceuticals (Berlin, Germany), Bracco 561 (Milano, Italy), and Guerbet (Villepinte, France)).

$562{ }^{d}$ Gadolinium consumption in Switzerland was not known, and thus was extrapolated from the 563 consumption in the hospital in Baden (3.1 kg, total 6728 MRI treatments) to all of 564 Switzerland (340,376 MRI treatments).

$565{ }^{e}$ Ratio of pharmaceuticals dispensed inside hospitals to total consumption, calculated by sales 566 data from IMS Health (Danbury, CT, USA). 
${ }^{f}$ Outpatient-adjusted ratio of pharmaceuticals dispensed inside hospitals to total consumption

568 (average case).

$569{ }^{g}$ Outpatient-adjusted ratio of pharmaceuticals dispensed inside hospitals to total consumption

570 (high case).

$571{ }^{h}$ References ${ }^{16,20,40-43,50}$. Excretion and elimination of iobitridol was assumed to be similar to

572 the other ICM, as no relevant literature was available.

\section{REFERENCES}

575 1. Weissbrodt, D.; Kovalova, L.; Ort, C.; Pazhepurackel, V.; Moser, R.; Hollender, J.;

576 Siegrist, H.; McArdell, C. S., Mass flows of X-ray contrast media and cytostatics in hospital

577 wastewater. Environ. Sci. Technol. 2009, 43, (13), 4810-4817.

578 2. Verlicchi, P.; Galletti, A.; Petrovic, M.; Barceló, D., Hospital effluents as a source of 579 emerging pollutants: An overview of micropollutants and sustainable treatment options. $J$. 580 Hydrol. 2010, 389, (3-4), 416-428.

581 3. Santos, L. H. M. L. M.; Gros, M.; Rodriguez-Mozaz, S.; Delerue-Matos, C.; Pena, A.; 582 Barceló, D.; Montenegro, M. C. B. S. M., Contribution of hospital effluents to the load of 583 pharmaceuticals in urban wastewaters: Identification of ecologically relevant pharmaceuticals.

584 Sci. Total Environ. 2013, 461-462, (0), 302-316.

585 4. Carraro, E.; Bonetta, S.; Bertino, C.; Lorenzi, E.; Bonetta, S.; Gilli, G., Hospital effluents 586 management: Chemical, physical, microbiological risks and legislation in different countries.

587 J. Environ. Manage. 2016, 168, 185-199.

588 5. Ort, C.; Lawrence, M. G.; Reungoat, J.; Eaglesham, G.; Carter, S.; Keller, J., Determining 589 the fraction of pharmaceutical residues in wastewater originating from a hospital. Water Res. 590 2010, 44, (2), 605-615.

591 6. Escher, B. I.; Baumgartner, R.; Koller, M.; Treyer, K.; Lienert, J.; McArdell, C. S., 592 Environmental toxicology and risk assessment of pharmaceuticals from hospital wastewater. 593 Water Res. 2011, 45, (1), 75-92.

594 7. Le Corre, K. S.; Ort, C.; Kateley, D.; Allen, B.; Escher, B. I.; Keller, J.,

595 Consumption-based approach for assessing the contribution of hospitals towards the load of

596 pharmaceutical residues in municipal wastewater. Environ. Int. 2012, 45, (0), 99-111.

597 8. Al Aukidy, M.; Verlicchi, P.; Voulvoulis, N., A framework for the assessment of the 598 environmental risk posed by pharmaceuticals originating from hospital effluents. Sci. Total 599 Environ. 2014, 493, (0), 54-64.

600 9. Daouk, S.; Chèvre, N.; Vernaz, N.; Widmer, C.; Daali, Y.; Fleury-Souverain, S., 601 Dynamics of active pharmaceutical ingredients loads in a Swiss university hospital 602 wastewaters and prediction of the related environmental risk for the aquatic ecosystems. Sci.

603 Total Environ. 2016, 547, 244-253.

604 10. Hospital beds (per 1,000 people). World Bank Open Data;

605 http://data.worldbank.org/indicator/SH.MED.BEDS.ZS?page=1. Accessed: 2015-03-09.

606 (Archived by WebCite ${ }^{\circledR}$ at http://www.webcitation.org/6WtAd0sR8)

607 11. Thomas, K. V.; Dye, C.; Schlabach, M.; Langford, K. H., Source to sink tracking of

608 selected human pharmaceuticals from two Oslo city hospitals and a wastewater treatment 
609 works. J. Environ. Monitor. 2007, 9, (12), 1410-1418.

610 12. Verlicchi, P.; Al Aukidy, M.; Galletti, A.; Petrovic, M.; Barceló, D., Hospital effluent:

611 Investigation of the concentrations and distribution of pharmaceuticals and environmental risk 612 assessment. Sci. Total Environ. 2012, 430, (0), 109-118.

613 13. Heberer, T.; Feldmann, D., Contribution of effluents from hospitals and private

614 households to the total loads of diclofenac and carbamazepine in municipal sewage

615

616

617

618

619

620

621

622

623

624

625

626

627

628

629

630

631

632

633

634

635

636

637

638

639

640

641

642

643

644

645

646

647

648 effluents - modeling versus measurements. J. Hazard. Mater. 2005, 122, (3), 211-218. 14. Emmanuel, E.; Perrodin, Y.; Keck, G.; Blanchard, J. M.; Vermande, P., Ecotoxicological risk assessment of hospital wastewater: a proposed framework for raw effluents discharging into urban sewer network. J. Hazard. Mater. 2005, 117, (1), 1-11.

15. Orias, F.; Perrodin, Y., Characterisation of the ecotoxicity of hospital effluents: A review. Sci. Total Environ. 2013, 454-455, (0), 250-276.

16. Ternes, T. A.; Hirsch, R., Occurrence and behavior of X-ray contrast media in sewage facilities and the aquatic environment. Environ. Sci. Technol. 2000, 34, (13), 2741-2748.

17. Kümmerer, K.; Haiß, A.; Schuster, A.; Hein, A.; Ebert, I., Antineoplastic compounds in the environment—substances of special concern. Environ. Sci. Pollut. R. 2014, 1-14.

18. Watkinson, A. J.; Murby, E. J.; Kolpin, D. W.; Costanzo, S. D., The occurrence of antibiotics in an urban watershed: From wastewater to drinking water. Sci. Total Environ. 2009, 407, (8), 2711-2723.

19. Michael, I.; Rizzo, L.; McArdell, C. S.; Manaia, C. M.; Merlin, C.; Schwartz, T.; Dagot, C.; Fatta-Kassinos, D., Urban wastewater treatment plants as hotspots for the release of antibiotics in the environment: A review. Water Res. 2013, 47, (3), 957-995.

20. Joss, A.; Keller, E.; Alder, A. C.; Göbel, A.; McArdell, C. S.; Ternes, T.; Siegrist, H., Removal of pharmaceuticals and fragrances in biological wastewater treatment. Water Res. 2005, 39, (14), 3139-3152.

21. Göbel, A.; Thomsen, A.; McArdell, C. S.; Joss, A.; Giger, W., Occurrence and sorption behavior of sulfonamides, macrolides, and trimethoprim in activated sludge treatment. Environ. Sci. Technol. 2005, 39, 3981-3989.

22. Pauwels, B.; Verstraete, W., The treatment of hospital wastewater: an appraisal. J. Water Health 2006, 4, 405-416.

23. Lienert, J.; Koller, M.; Konrad, J.; McArdell, C. S.; Schuwirth, N., Multiple-criteria decision analysis reveals high stakeholder preference to remove pharmaceuticals from hospital wastewater. Environ. Sci. Technol. 2011, 45, (9), 3848-3857.

24. Hollender, J.; Zimmermann, S. G.; Koepke, S.; Krauss, M.; McArdell, C. S.; Ort, C.; Singer, H.; von Gunten, U.; Siegrist, H., Elimination of organic micropollutants in a municipal wastewater treatment plant upgraded with a full-scale post-ozonation followed by sand filtration. Environ. Sci. Technol. 2009, 43, (20), 7862-7869.

25. Reungoat, J.; Escher, B. I.; Macova, M.; Argaud, F. X.; Gernjak, W.; Keller, J., Ozonation and biological activated carbon filtration of wastewater treatment plant effluents. Water Res. 2012, 46, (3), 863-872.

26. Margot, J.; Kienle, C.; Magnet, A.; Weil, M.; Rossi, L.; de Alencastro, L. F.; Abegglen, C.; Thonney, D.; Chèvre, N.; Schärer, M.; Barry, D. A., Treatment of micropollutants in municipal wastewater: Ozone or powdered activated carbon? Sci. Total Environ. 2013, 461-462, (0), 480-498.

27. Mikroverunreinigungen: Massnahmen bei der Abwasserreinigung (Micropollutants: measures in wasteater treatment). Federal Office for Environment (FOEN), Switzerland Website (in German); http://www.bafu.admin.ch/gewaesserschutz/03716/index.html?lang=en. Accessed: 2015-03-09. (Archived by WebCite ${ }^{\circledR}$ at http://www.webcitation.org/6WtI9NAAf) 28. Eggen, R. I. L.; Hollender, J.; Joss, A.; Schärer, M.; Stamm, C., Reducing the discharge of micropollutants in the aquatic environment: The benefits of upgrading wastewater 
659 treatment plants. Environ. Sci. Technol. 2014, 48, (14), 7683-7689.

660 29. Ort, C.; Hollender, J.; Schaerer, M.; Siegrist, H., Model-based evaluation of reduction

661 strategies for micropollutants from wastewater treatment plants in complex river networks.

662 Environ. Sci. Technol. 2009, 43, (9), 3214-3220.

663 30. Verlicchi, P.; Al Aukidy, M.; Jelic, A.; Petrović, M.; Barceló, D., Comparison of

664 measured and predicted concentrations of selected pharmaceuticals in wastewater and surface

665 water: A case study of a catchment area in the Po Valley (Italy). Sci. Total Environ. 2014,

666 470-471, (0), 844-854.

667 31. Kehrein, N.; Berlekamp, J.; Klasmeier, J., Modeling the fate of down-the-drain chemicals

668 in whole watersheds: New version of the GREAT-ER software. Environ. Modell. Softw. 2015,

$66964,1-8$.

670 32. Price, O. R.; Williams, R. J.; Zhang, Z.; van Egmond, R., Modelling concentrations of

671 decamethylcyclopentasiloxane in two UK rivers using LF2000-WQX. Environ. Pollut. 2010,

$672158,(2), 356-360$.

673 33. Coppens, L. J. C.; van Gils, J. A. G.; ter Laak, T. L.; Raterman, B. W.; van Wezel, A. P.,

674 Towards spatially smart abatement of human pharmaceuticals in surface waters: Defining

675 impact of sewage treatment plants on susceptible functions. Water Res. 2015, 81, 356-365.

676 34. Knodel, J.; Geißen, S. U.; Broll, J.; Dünnbier, U., Simulation and source identification of

677 X-ray contrast media in the water cycle of Berlin. J. Environ. Manage. 2011, 92, (11),

$678 \quad 2913-2923$.

679 35. Van Boeckel, T. P.; Gandra, S.; Ashok, A.; Caudron, Q.; Grenfell, B. T.; Levin, S. A.;

680 Laxminarayan, R., Global antibiotic consumption 2000 to 2010: an analysis of national

681 pharmaceutical sales data. Lancet Infect. Dis. 14, (8), 742-750.

682 36. Ort, C.; Lawrence, M. G.; Reungoat, J.; Mueller, J. F., Sampling for PPCPs in wastewater

683 systems: Comparison of different sampling modes and optimization strategies. Environ. Sci.

684 Technol. 2010, 44, (16), 6289-6296.

685 37. Lawrence, M. G.; Ort, C.; Keller, J., Detection of anthropogenic gadolinium in treated

686 wastewater in South East Queensland, Australia. Water Res. 2009, 43, (14), 3534-3540.

687 38. Verplanck, P. L.; Furlong, E. T.; Gray, J. L.; Phillips, P. J.; Wolf, R. E.; Esposito, K.,

688 Evaluating the behavior of gadolinium and other rare earth elements through large

689 metropolitan sewage treatment plants. Environ. Sci. Technol. 2010, 44, (10), 3876-3882.

690 39. Janna, H.; Scrimshaw, M. D.; Williams, R. J.; Churchley, J.; Sumpter, J. P., From

691 dishwasher to tap? Xenobiotic substances benzotriazole and tolyltriazole in the environment.

692 Environ. Sci. Technol. 2011, 45, (9), 3858-3864.

693 40. Kovalova, L.; Siegrist, H.; Singer, H.; Wittmer, A.; McArdell, C. S., Hospital wastewater

694 treatment by membrane bioreactor: Performance and efficiency for organic micropollutant

695 elimination. Environ. Sci. Technol. 2012, 46, (3), 1536-1545.

696 41. Batt, A. L.; Kim, S.; Aga, D. S., Enhanced biodegradation of iopromide and trimethoprim

697 in nitrifying activated sludge. Environ. Sci. Technol. 2006, 40, (23), 7367-7373.

698 42. Ternes, T. A.; Bonerz, M.; Herrmann, N.; Teiser, B.; Andersen, H. R., Irrigation of

699 treated wastewater in Braunschweig, Germany: An option to remove pharmaceuticals and

700 musk fragrances. Chemosphere 2007, 66, (5), 894-904.

701 43. Kormos, J. L.; Schulz, M.; Ternes, T. A., Occurrence of iodinated X-ray contrast media

702 and their biotransformation products in the urban water cycle. Environ. Sci. Technol. 2011,

703 45, (20), 8723-8732.

704 44. Menz, J.; Schneider, M.; Kümmerer, K., Usage pattern-based exposure screening as a

705 simple tool for the regional priority-setting in environmental risk assessment of veterinary

706 antibiotics: A case study of north-western Germany. Chemosphere 2015, 127, 42-48.

707 45. Kovalova, L.; Siegrist, H.; Von Gunten, U.; Eugster, J.; Hagenbuch, M.; Wittmer, A.;

708 Moser, R.; McArdell, C. S., Elimination of micropollutants during post-treatment of hospital 
709 wastewater with powdered activated carbon, ozone and UV. Environ. Sci. Technol. 2013, 47, 710 (14), 7899-7908.

711 46. Kuroda, K.; Murakami, M.; Oguma, K.; Muramatsu, Y.; Takada, H.; Takizawa, S., 712 Assessment of groundwater pollution in Tokyo using PPCPs as sewage markers. Environ. Sci. 713 Technol. 2012, 46, (3), 1455-1464.

714 47. Phillips, P. J.; Chalmers, A. T.; Gray, J. L.; Kolpin, D. W.; Foreman, W. T.; Wall, G. R., 715 Combined sewer overflows: An environmental source of hormones and wastewater 716 micropollutants. Environ. Sci. Technol. 2012, 46, (10), 5336-5343.

717 48. Buerge, I. J.; Buser, H.-R.; Poiger, T.; Müller, M. D., Occurrence and fate of the

718 cytostatic drugs cyclophosphamide and ifosfamide in wastewater and surface waters. Environ. 719 Sci. Technol. 2006, 40, (23), 7242-7250.

720 49. Luo, Y.; Guo, W.; Ngo, H. H.; Nghiem, L. D.; Hai, F. I.; Zhang, J.; Liang, S.; Wang, X. C., A review on the occurrence of micropollutants in the aquatic environment and their fate and removal during wastewater treatment. Sci. Total Environ. 2014, 473-474, (0), 619-641. 50. Deblonde, T.; Cossu-Leguille, C.; Hartemann, P., Emerging pollutants in wastewater: A review of the literature. Int. J. Hyg. Envir. Heal. 2011, 214, (6), 442-448. 